\title{
When is a species at risk in 'all or a significant portion of its range'?
}

\author{
Robin S. Waples ${ }^{1, *}$, Peter B. Adams ${ }^{2, * *}$, James A. Bohnsack ${ }^{3}$, Barbara L. Taylor ${ }^{4}$ \\ ${ }^{1}$ Northwest Fisheries Science Center, 2725 Montlake Blvd. East, Seattle, WA 98112, USA \\ ${ }^{2}$ Southwest Fisheries Science Center, 110 Shaffer Road, Santa Cruz, CA 95060, USA \\ ${ }^{3}$ Southeast Fisheries Science Center, 75 Virginia Beach Drive, Miami, FL 33149, USA \\ ${ }^{4}$ Southwest Fisheries Science Center, 8604 La Jolla Shores Drive, La Jolla, CA 92037, USA
}

\begin{abstract}
The US Endangered Species Act (ESA) allows protection of any species that is at risk in all or 'a significant portion of its range' (SPOIR). Because this provision is open to many possible interpretations, the agencies responsible for implementing the ESA recently published a SPOIR policy. The policy is based on a framework we developed that asks a simple question: 'If the portions of the range that are currently at risk were lost, would the entire species, at that point, be threatened or endangered?' If so, the portion of the range is significant. Some commentators have argued that the policy departs from goals the ESA was originally intended to accomplish. We disagree; biologists and managers struggling to implement provisions of the ESA in complex, realworld situations need practical guidance, and we believe our framework provides that. In particular, it avoids as much as possible normative considerations in evaluating 'significance' in terms of human values; instead, we focus on significance to the species, which is consistent with the ESA focus on preventing extinctions, as well as with the mandate that listing determinations be based 'solely' on scientific information. However, we agree with some critics that a crucial factor in implementation of the policy will be how historical versus current concepts of range are reconciled. We believe that historical distribution and abundance are important, not as specific restoration goals, but as reference points that characterize conditions under which we are confident the species was viable.
\end{abstract}

KEY WORDS: Endangered species - Endangered Species Act · Threatened - Endangered · Significant portion $\cdot$ Viability $\cdot$ Historical template $\cdot$ Policy

\section{INTRODUCTION}

Implementing legal conservation mandates in the real world is a challenging enterprise, particularly when vague or ambiguous regulatory language has to be translated into concrete actions. A recent example involves the mandate in the US Endangered Species Act (ESA) to conserve any species that is threatened or endangered in 'all or a significant portion of its range' (SPOIR). Because this curious phrase is open to many possible interpretations yet can have a substantial influence on federal programs for conservation of biodiversity, the 2 agencies responsible for administering the ESA (the Fish and Wildlife Service [FWS] and the National Marine Fisheries Service [NMFS]) recently finalized a policy describing how they will interpret the SPOIR language (FWS \& NMFS 2014). This event triggered several strongly negative responses (Nelson \& Vucetich 2014, Vucetich \& Nelson 2014, Mernit 2014) that characterized 
the new policy as a giant step away from what the ESA was originally intended to accomplish. We believe Endangered Species Research is the most suitable forum for a response to these comments because it allows for a full discussion of the complex issues involved.

\section{BACKGROUND}

The ESA (Section 4) defines an endangered species as one that is 'in danger of extinction throughout all or a SPOIR' and a threatened species as one that is 'likely to become an endangered species within the foreseeable future throughout all or a SPOIR.' (The ESA definition of 'species' includes named subspecies and 'distinct population segments' of vertebrates, so the SPOIR language can apply to any of these entities.) Although these definitions have been in place for over $30 \mathrm{yr}$, the SPOIR language was largely ignored until the last decade or so, when courts and stakeholders began to take a keen interest. One federal judge found the SPOIR language 'puzzling' and 'enigmatic' (Defenders of Wildlife v. Norton, 258 F.3d 1136, 1141; 9th Cir. 2001). The resulting confusion and uncertainty regarding how the SPOIR language should be interpreted (see summary by Office of the Solicitor [2007]) emphasized the need for the agencies to develop a SPOIR policy. In 2005, we were asked by our agency (NMFS) to develop a biological framework for interpreting the SPOIR language. We finalized our report in 2006, and a reformatted version was published as a journal article the next year (Waples et al. 2007a). The framework we proposed asks a simple question in cases where a species is at risk in part but not all of its range: 'If the portions of the range that are currently at risk were lost, at that point would the entire species be Threatened or Endangered?' If so, the portion of the range is significant. Concurrently, Vucetich et al. (2006) published a paper in which they argued that specifying conditions for endangerment is largely a normative exercise, and that the ESA uses the SPOIR provision to identify risks of extinction that are unacceptable because they apply to large portions of a species' range. The main difference between our framework and the vision of Vucetich \& Nelson is the point of reference for evaluating significance: they focus on importance to humans, whereas our framework emphasizes importance to the species itself. A series of comments and responses captured some of the divergent viewpoints on this issue (Nelson et al. 2007, Waples et al. 2007b, 2008, D'Elia et al. 2008). In late 2011 the agen- cies published a draft SPOIR policy (FWS \& NMFS 2011); two and a half years later, following an extensive public comment period, the policy was finalized (FWS \& NMFS 2014). Both the draft and final SPOIR policies adopted the basic biological framework we proposed for determining when a portion of a species' range is 'significant.'

\section{WHAT ARE THE CHARACTERISTICS OF A GOOD POLICY?}

The ESA mandates that all listing decisions be based 'solely' on the best available scientific information, yet requires managers and scientists alike to do so in the context of statutory language for which no accepted scientific definitions exist. As emphasized by the judicial response to Defenders of Wildlife $v$. Norton, this created a situation in which the SPOIR language could be (and was) interpreted in various ways in different applications for different species. As a consequence, those who might be affected by a new listing determination had little basis for predicting how the agencies would handle a new case. An effective conservation policy should aim to strike a delicate balance between rigidity and flexibility; it should not be so rigid that it constrains the ability to accommodate important nuances inherent to all biological systems, but it should provide enough guidance to promote consistency in its application and to allow others to reasonably predict the consequences of new applications.

We believe the biological framework we proposed for interpreting the SPOIR language in the ESA can form the basis for effective public policy. Our interpretation of 'significant' in terms of effects on the viability of the species itself is consistent with the focus of the ESA on preventing extinctions, as well as with the ESA mandate that listing determinations be scientifically based. Although our framework can be challenging to apply, it is objective and conceptually simple and should help promote consistency and predictability, exactly as a policy should. In contrast, if the portion of a species' range that is considered 'significant' depends instead on societal values and other subjective assessments, as proposed by Vucetich et al. (2006), then every 'SPOIR' evaluation becomes a unique exercise, with results that are impossible to predict in advance.

Of course, a good policy should also be consistent with broader goals and objectives, and the recent commenters feel that the new SPOIR policy deviates substantially from the original intent of the ESA. Nel- 
son \& Vucetich (2014) argued that the new policy 'severely diminishes' a basic aspiration for conservation under the ESA, and that a 'plain language' reading of the ESA definition of an endangered species is 'one whose geographic range has been significantly diminished by human hubris.' Vucetich \& Nelson (2014) compared the new policy to 'curating rare pieces in a museum;' they argued that a goal more commensurate with Congress's intent in passing the ESA would be to restore species to all portions of their historic range that are suitable or can be made suitable. Mernit (2014) asked whether the Obama administration has 'hobbled' the ESA and quoted Noah Greenwald, from the Center for Biological Diversity, as stating that the ESA 'was designed to retain species in ecosystems that depend upon them.'

Do we support restoration of species to the point at which they are important players in their ecosystems as a general aspirational goal for society? Absolutely. However, we do not believe the above criticisms hold up to careful scrutiny. Guessing the motivations and intent of Congress in passing legislation is tricky, and reasonable people can come to very different conclusions (Callicot 2006, Illical \& Harrison 2007, Doremus 2010). In practice, species conservation under the ESA has to be implemented within the constraints of the law as it is actually written, not in the context of how one wishes it had been written. Ecosystems are important to the ESA, but not just any ecosystems; it is, after all, the Endangered Species Act, not the Endangered Ecosystems Act. The stated purposes of the ESA (Section 2[b]) include conservation of ecosystems 'upon which endangered species and threatened species depend,' as well as the species themselves. That is, contrary to the quote attributed to Greenwald, the ESA is not about conserving species because ecosystems depend upon them; it is about conserving threatened and endangered species and the ecosystems those species require (Ashe \& Sobeck 2014). The close link between species and their native ecosystems determines their viability, and that link is the focus of our framework for interpreting the 'significant portion of its range' language in the ESA.

We do agree with these commenters that how the National Marine Fisheries Service and US Fish and Wildlife Service deal with current versus historical interpretations of 'range' will be crucial to implementation of the policy. The new policy argues that a species cannot at present be threatened or endangered in portions of its range where it no longer exists. Although this might be technically correct, in the absence of historical context, risk assessments can suffer from the shifting baselines syndrome, whereby greatly reduced status is perceived as 'normal.' Waples et al. (2008) warned that this syndrome could diminish the effectiveness of conservation under some possible interpretations of the SPOIR language. However, the new policy also states that 'evaluating the effects of lost historical range on the viability of the species is an important component of evaluating the current status of the species' (FWS \& NMFS 2014). Therefore, a great deal will depend on how these 2 contrasting aspects of the policy are balanced in its implementation. The framework we developed places considerable emphasis on the 'historical template,' which includes not only distribution and abundance, but also key demographic/ecological processes like migration. The historical template is important not as a specific restoration goal, but as a description of the conditions under which we are confident the species was viable. When we encounter a species whose current status is far from its historical template, we see red flags that demand an answer to the question, 'Can this species be viable into the future, even though it is greatly diminished from its former status?'

We believe the framework we developed for interpreting the SPOIR language can provide practical and badly needed guidance regarding ESA implementation, while allowing agencies the flexibility to deal with the complexities that inevitably arise in biological systems. One complexity that is becoming increasingly important to consider is the response of species to anthropogenic changes to their environments, including climate change (McClure et al. 2013). Although the historical template is useful in informing us about factors that have combined to allow species to be viable in the past, it will be necessary to expand this concept to include consideration of elements of the species 'range' that are necessary to ensure viability in future ecosystems, which might be quite different.

Acknowledgements. The views expressed in this article are those of the authors and are not official positions of NOAA Fisheries.

\section{LITERATURE CITED}

Ashe D, Sobeck E (2014) Using scarce resources to save endangered species. The New York Times, 4 September 2014

Callicot JB (2006) Explicit and implicit values. In: Scott JM, Goble DD, Davis FW (eds) The Endangered Species Act at thirty: conserving biodiversity in human-dominated landscapes. Island Press, Washington, DC, p 36-48

> D'Elia J, Zwartjes M, McCarthy S (2008) Considering legal viability and societal values when deciding what to con- 
serve under the US Endangered Species Act. Conserv Biol 22:1072-1074

Doremus H (2010) The Endangered Species Act: static law meets dynamic world. Wash Univ J Law Policy 32:175-235

FWS and NMFS (Fish and Wildlife Service and National Marine Fisheries Service) (2011) Draft policy on interpretation of the phrase 'significant portion of its range' in the Endangered Species Act's definitions of 'Endangered species' and 'Threatened species'. Fed Regist 76: 76987-77006

FWS and NMFS (2014) Final policy on interpretation of the phrase 'significant portion of its range' in the Endangered Species Act's definitions of 'Endangered Species' and 'Threatened Species'. Fed Regist 79:37578-37612

Illical M, Harrison K (2007) Protecting endangered species in the US and Canada: the role of negative lesson drawing. Can J Polit Sci 40:376-394

McClure MM, Crozier LG, Boughton DA, Alexander MA and others (2013) Incorporating climate science in applications of the US Endangered Species Act for aquatic species. Conserv Biol 27:1222-1233

Mernit JL (2014) A significant turn of phrase: Has the Obama administration hobbled the Endangered Species Act? High Country News 46:3-5. www.hcn.org/issues/46.17/ has-the-obama-administration-hobbled-the-endangeredspecies-act (accessed 19 March 2015)

Nelson MP, Vucetich JA (2014) The future of conservation and the tragedy of triage. The Huffington Post, 23 September 2014. www.huffingtonpost.com/michael-p-nelson/

Editorial responsibility: Brendan Godley,

University of Exeter, Cornwall Campus, UK the-future-of-conservatio_b_5870568.html (accessed 19 March 2015)

Nelson MP, Vucetich JA, Phillips MK (2007) Normativity and the meaning of endangered: a response to Waples et al. 2007. Conserv Biol 21:1646-1648

Office of the Solicitor (2007) The meaning of 'in danger of extinction throughout all or a significant portion of its range.' Memorandum M-37013 from the Solicitor to the Director of the US Fish and Wildlife Service (16 March). US Department of the Interior, Office of the Solicitor, Washington, DC. www.doi.gov/solicitor/opinions/M37013.pdf (accessed 19 March 2015)

Vucetich JA, Nelson MP (2014) Conservation, or curation? The New York Times, 21 August 2014. www.nytimes. com/2014/08/21/opinion/conservation-or-curation.html? $\mathrm{r}=0$ (accessed )

> Vucetich JA, Nelson MP, Phillips MK (2006) The normative dimension and legal meaning of endangered and recovery in the U.S. Endangered Species Act. Conserv Biol 20: 1383-1390

Waples RS, Adams PB, Bohnsack J, Taylor BL (2007a) A biological framework for evaluating whether an ESA species is threatened or endangered in a 'significant portion of its range'. Conserv Biol 21:964-974

> Waples RS, Adams PB, Bohnsack J, Taylor BL (2007b) Normativity redux. Conserv Biol 21:1649-1650

- Waples RS, Adams PB, Bohnsack J, Taylor BL (2008) Legal viability, societal values, and SPOIR: response to D'Elia et al. Conserv Biol 22:1075-1077

Submitted: January 5, 2015; Accepted: February 4, 2015 Proofs received from author(s): March 19, 2015 